Published in final edited form as:

Antiviral Res. 2007 March ; 73(3): 212-218.

\title{
ORAL 1-O-OCTADECYL-2-O-BENZYL-SN-GLYCERO-3-
}

CIDOFOVIR TARGETS THE LUNG AND IS EFFECTIVE AGAINST A LETHAL RESPIRATORY CHALLENGE WITH ECTROMELIA VIRUS

\section{IN MICE}

\author{
Karl Y. Hostetler ${ }^{\dagger}$, James R. Beadle, Julissa Trahan, Kathy A. Aldern, Gelita Owens ${ }^{a}$, Jill \\ Schriewera, Lora Melman ${ }^{\mathrm{a}}$, and R. Mark Bullera \\ Department of Medicine, Division of Infectious Disease, University of California, San Diego, La Jolla, CA \\ 92093-0676, the Veterans Medical Research Foundation, San Diego, CA 92161
}

a Department of Molecular Microbiology and Immunology, Saint. Louis University Health Sciences Center, St. Louis, MO 63104

\begin{abstract}
Hexadecyloxypropyl-cidofovir (HDP-CDV) has been shown to be orally active against lethal infection with orthopoxviruses including, mousepox, cowpox, vaccinia and rabbitpox. The alkoxyalkyl group provides oral absorption and reduces greatly the amount of drug reaching the kidney, the site of CDV's dose limiting toxicity. However, the amount of HDP-CDV detected in lung, an important site of early poxvirus replication, is low and the reduction of viral titers in surviving animals is reduced moderately compared with the liver where poxvirus titers are virtually undetectable. We synthesized a novel glycerol ester of CDV, 1-O-octadecyl-2-O-benzyl-snglycero-3-CDV (ODBG-CDV), and compared its oral pharmacokinetics with that of HDP-CDV. Surprisingly, ODBG-CDV levels in lung are much higher and liver levels are reduced, suggesting that the compound is transported in small intestinal lymph instead the portal vein. ODBG-CDV has excellent in vitro activity in cells infected with ectromelia virus (ECTV). In mice infected with a lethal aerosol or intranasal challenge of ECTV, HDP-CDV and ODBG-CDV are equally effective in preventing death from disease. Other drugs esterified to 1-O-octadecyl-2-O-benzyl-sn-glycerol or 1-O-octadecyl-2-O-benzyl-sn-glycerol-3-phosphate may provide lung targeting for treatment of microbial or neoplastic diseases while reducing first pass removal by the liver during oral absorption.
\end{abstract}

\section{Keywords}

ectromelia virus; cidofovir; prodrugs; lung targeting

\footnotetext{
${ }^{\dagger}$ Corresponding author: Karl Y. Hostetler, Dept. of Medicine (0676), Univ. of California, San Diego, 9500 Gilman Drive, La Jolla, CA 92093-0676, Telephone: (858) 552-8585 ext 2616., Fax: (858) 534-6133., Email: khostetl@ucsd.edu.

Publisher's Disclaimer: This is a PDF file of an unedited manuscript that has been accepted for publication. As a service to our customers we are providing this early version of the manuscript. The manuscript will undergo copyediting, typesetting, and review of the resulting proof before it is published in its final citable form. Please note that during the production process errors may be discovered which could affect the content, and all legal disclaimers that apply to the journal pertain.

* Portions of this paper were presented in abstract form at the International Conference on Antiviral Research, April 11-14, 2005, Barcelona, Spain
} 


\section{INTRODUCTION}

It has been previously reported that alkoxyalkyl analogs of acyclic nucleoside phosphonates like hexadecyloxypropyl-cidofovir (HDP-CDV) are orally bioavailable and active in lethal orthopoxvirus challenge models ( Buller et al, 2004; Quenelle et al, 2004). However, oral pharmacokinetics with radiolabeled HDP-CDV (Ciesla et al, 2003) show low levels of drug and metabolites in the lung, an important site of early poxvirus replication. We reported previously that 1-O-octadecyl-2-O-benzyl-sn-glycero-cidofovir (ODBG-CDV; Figure 1) was active against cowpox and vaccinia virus strains with $50 \%$ effective concentration values ( $\mathrm{EC}_{50}$ ) ranging from 0.09 to $0.4 \mu \mathrm{M}$ (Wan et al, 2005). ODBG-CDV was also highly active against HCMV, ganciclovir-resistant and phosphonformate-resistant isolates of HCMV, HSV-1, HSV-2, VZV, EBV, HHV-6A, HHV-6B and HHV-8 with EC $_{50}$ values in the nanomolar range (Williams-Aziz et al, 2005). In vaccinia infection in organotypic epithelial raft cultures of primary human keratinocytes, ODBG-CDV was the most active analog of CDV with an $\mathrm{EC}_{90}$ value $<0.04 \mu \mathrm{M}$ (LeBeau et al, 2006).

We prepared ODBG-[2- $\left.{ }^{14} \mathrm{C}\right]-\mathrm{CDV}$ to assess oral and parenteral pharmacokinetics. The compound was given orally and intraperitoneally to mice and tissue and plasma levels of radiolabeled drug and metabolites were measured at various times up to 72 hours. Relative oral bioavailability was determined from the plasma area under curve (AUC) obtained with oral versus intraperitoneal administration. Tissue distribution of drug and metabolites was assessed in liver, kidney, and lung. Surprisingly, oral ODBG-[2-14C]-CDV produced very high levels of drug and metabolites in lung compared with oral HDP- $\left[2-{ }^{14} \mathrm{C}\right] \mathrm{CDV}$, indicating that oral ODBG-[2- $\left.{ }^{14} \mathrm{C}\right]-\mathrm{CDV}$ targets the lung in mice. ODBG-CDV and HDP-CDV were evaluated orally in aerosol and intranasal ectromelia virus (ECTV) lethal challenge models. Both compounds were highly effective in preventing death from disease.

\section{METHODS}

\subsection{Chemistry}

1-O-Octadecyl-2-O-benzyl-sn-glycerol was purchased from Bachem, Torrance, CA. 1-OOctadecyl-2-O-benzyl-sn-glycero-3-cidofovir was synthesized as previously described (Wan et al, 2005). Briefly, anhydrous cCDV (1 equiv), 1-O-octadecyl-2-O-benzyl-sn-glycerol (2 equiv), and triphenylphosphine (2 equiv) were dissolved/suspended in anhydrous N,N-DMF (6.5 $\mathrm{mL}$ per $\mathrm{mmol}$ of cCDV), and stirred vigorously under a nitrogen atmosphere. Diisopropyl azadicarboxylate (DIAD, 2 equiv) was then added in three equal portions over 15 minutes before the mixture was allowed to stir overnight. The solvent was then evaporated under vacuum and the residue purified by column chromatography with silica gel and recrystallized from p-dioxane. The cyclic CDV ring was opened with base (Wan et al, 2005). Using this method, ODBG-[2- $\left.{ }^{14} \mathrm{C}\right]-\mathrm{CDV}$ was prepared by Moravek Biochemicals, Inc. (Brea, CA). The structures of HDP-CDV and ODBG-CDV are shown in Figure 1.

\subsection{Animal Pharmacokinetic Studies}

Female Swiss-Webster mice weighing approximately 25 grams received a single dose of 10 $\mathrm{mg} / \mathrm{kg}$ ODBG-[2- $\left.{ }^{14} \mathrm{C}\right]-\mathrm{CDV}$ (specific activity, $53 \mathrm{mCi} / \mathrm{mmol}$ ) in sterile $0.9 \%$ saline either by oral gavage or by intraperitoneal injection. Three animals were sacrificed at 1, 3, 6, 12, 24, 48, and 72 hours and blood and tissue samples were obtained. Fifty $\mu$ l of plasma was added to 10 $\mathrm{ml}$ of Ecolite cocktail and analyzed for drug and metabolite content by a scintillation counting. The kidney, lung and liver were also obtained from each mouse, washed with $0.9 \%$ saline, and weighed. The tissue was treated with $3 \mathrm{ml} \mathrm{TS}-2$ tissue solubilizer and $0.5 \mathrm{ml}$ of water and placed in a $50^{\circ} \mathrm{C}$ water bath for $36-48$ hours. Glacial acetic acid was added to each vial to 
neutralize the TS-2 and Flo-Scint IV was added before counting. Plasma pharmacokinetic data was calculated as reported previously (Ciesla et al, 2003).

\subsection{HPLC Analysis of Metabolites}

Lung and Liver Tissue-Twenty percent homogenates of liver and lung tissue were made in ultrapure distilled water saline and aliquots were reserved frozen at $-70^{\circ} \mathrm{C}$ until analysis. A portion of the liver and lung homogenates was frozen and thawed two times in an isopropanol/dry ice bath and then sonicated on ice in a bath sonicator for $5 \mathrm{~min}$. Trichloroacetic acid was added to a $7 \%$ final concentration and centrifuged at $4^{\circ} \mathrm{C}$ for $10 \mathrm{~min}$ at $1000 \mathrm{rpm}$. The supernatant was removed and aliquots counted in a scintillation counter. An aliquot representing approximately 10,000 DPM was analyzed by HPLC (System Gold, Beckman Coulter, Fullerton, CA). The samples were injected into a Partisil 10 SAX column (Alltech, Deerfield, IL), $4.6 \times 15 \mathrm{~cm}$, and a SAX guard column. Metabolites were eluted at a flow rate of $1 \mathrm{ml} / \mathrm{min}$ using a potassium phosphate buffer gradient of $20 \mathrm{mM}$ to $700 \mathrm{mM}, \mathrm{pH} 5.8$, beginning at $9 \mathrm{~min}$ for $20 \mathrm{~min}$ followed by a $5 \mathrm{~min}$ terminal hold. One minute fractions were collected and Ultima Flo scintillation fluid added and their content of radioactivity was determined by liquid scintillation. The identity of the radioactive peaks was compared with the retention time of pure standards of CDV, CDV-monophosphate (CDVp) and CDV-diphosphate (CDVpp). CDVp and CDVpp were obtained from TriLink Biotechnologies Inc. (San Diego, CA).

\subsection{Ectromelia Virus Studies}

Plaque reduction assay-BSC-1 cells were plated in wells of a 24 well cluster plate. Each monolayer was infected with $\sim 75$ plaque forming units (PFU) of indicator virus in $0.1 \mathrm{ml}$ of $\mathrm{DMEM}+2 \%$ Fetal clone II for $60 \mathrm{~min}$ at $37^{\circ} \mathrm{C}$. Media was removed by aspiration and standard virus overlay media containing no drug or the test drug at concentrations ranging from 0.05 to $50 \mu \mathrm{M}$ was added. The plates were incubated at $37^{\circ} \mathrm{C}$ for $3-4$ days and monolayers were stained and plaques counted using a stereomicroscope. The $\mathrm{EC}_{50}$ concentration for each drug was calculated.

Measurement of Cytotoxicity-Cytotoxicity was determined using Promega Cell Titer 96* Aqueous Non-radioactive Cell Proliferation Assay kit (G5421). BSC-1 cells were plated at $4 \times 10^{3}$ cells per well in a 96-well flat bottom plate and treated with serial dilutions of the test compounds for 48-72 hours then assayed using MTS dye. Four hours following the addition of the dye, the plates were read at $490 \mathrm{~nm}$ on an ELISA plate reader. The percent cytotoxicity was calculated and plotted against the concentration of the test compound to determine the $50 \%$ cytotoxic concentration $\left(\mathrm{CC}_{50}\right)$.

\subsection{Animals}

Four to six week old female A/NCR (A/JCr) mice were obtained from the National Cancer Institute, Frederick Md., housed in filter-top microisolator cages and fed commercial mouse chow and water, ad libitum. The mice were housed in a biosafety level 3 containment area. Animal husbandry and experimental procedures were in accordance with PHS policy, and approved by the Institutional Animal Care and Use Committee.

\subsection{In vivo drug evaluation}

Mice were exposed to aerosolized ECTV suspended in DMEM using a nose-only inhalation exposure system (NOIES; CH Technologies) equipped with a 1-jet BioAerosol Nebulizing Generator, and operated within a class II biological safety cabinet. The NOIES was operated with a primary air pressure of $20 \mathrm{psi}$ giving $2 \mathrm{~L} / \mathrm{min}$ flow rate to the aerosol chamber (without secondary air), a virus suspension flow rate of $0.5 \mathrm{ml} / \mathrm{min}$, and a system operating pressure 
-0.5 in of vacuum relative to the out-side atmospheric pressure. The NOIES delivered a predicted median particle diameter of $0.8 \pm 1.2 \mu \mathrm{m}$ (Dr. Chad Roy, personnel communication). The quantity of virus delivered to the mice over the course of exposure was not measured directly, but estimated by multiplying the concentration of virus in the aerosol $\left(\mathrm{C}_{\mathrm{A}}\right)$ in PFU by the total volume $\left(\mathrm{V}_{\mathrm{M}}\right)$ of air respired by a mouse of given body weight over the exposure time using Guyton's formula for minute volumes administered to rodents (Guyton, 1947). This presented virus dose is likely an upper limit as it assumes that all of the virus was optimally aerosolized and completely taken up on inhalation. In another experiment, ECTV was administered intranasally. Four hours following aerosol exposure to ECTV, groups of 10-13 mice were treated by gavage with $0.1 \mathrm{ml}$ sterile, distilled water alone or water containing HDPCDV or ODBG-CDV. This treatment was repeated on days 1,2,3, and 4 post-infection for a total of five doses. Mice were observed over 21 days for clinical signs of disease (morbidity) and mortality (mean time to death and number of mice killed). Mice showing conjunctivitis, little or no movement, or marked respiratory distress were euthanized as they were near death.

\subsection{Statistical methods}

Groups of mice treated with the test compounds were compared statistically to vehicle treated groups. Mortality rates were analyzed by Fisher's exact test. Day of death data were analyzed by Mann-Whitney U rank sum test. A p-value of 0.05 or less was considered significant.

\section{RESULTS}

\subsection{Antiviral Activity in vitro}

The antiviral activity of HDP-CDV and ODBG-CDV was evaluated in vitro in BSC- 1 cells infected with ECTV as reported previously (Buller et al, 2004). HDP-CDV had an $\mathrm{EC}_{50}$ value of $0.22 \mu \mathrm{M}$ versus $0.01 \mu \mathrm{M}$ for ODBG-CDV, and the $\mathrm{CC}_{50}$ values were 13.4 and $35 \mu \mathrm{M}$. The selectivity indexes for HDP-CDV and ODBG-CDV were 61 and 3,500, respectively.

\subsection{Pharmacokinetics of ODBG-CDV}

Plasma drug levels following a $10 \mathrm{mg} / \mathrm{kg}$ dose of ODBG-[2- $\left.{ }^{14} \mathrm{C}\right]-\mathrm{CDV}$ given orally and intraperitoneally were determined (Figure 2, panel A). In the oral group, plasma drug levels and metabolites peaked at $1.1 \mu \mathrm{M}$ at 6 hours compared to $10 \mu \mathrm{M}$ at 1 hour in the intraperitoneal group. Plasma CDV equivalents declined, rapidly reaching $0.03 \mu \mathrm{M}$ in the oral group and 0.07 $\mu \mathrm{M}$ in the intraperitoneal group at 72 hours. The plasma area under the curve (AUC) values for oral and intraperitoneal ODBG-[2- $\left.{ }^{14} \mathrm{C}\right]-\mathrm{CDV}$ were compared. The intraperitoneal group had a larger area under the curve; based on the comparative AUC values for oral and intraperitoneal ODBG-CDV, we estimated a relative oral bioavailability of $32.3 \%$ for ODBGCDV (Table 1). We previously used a similar approach to evaluate the oral absorption and tissue levels of HDP-[2-14 C]-CDV (Ciesla et al, 2003) and have included the data in Table 1 for comparison with ODBG-[2- $\left.{ }^{14} \mathrm{C}\right]-\mathrm{CDV}$. Oral ODGB-CDV shows a longer plasma half life $\left(\mathrm{T}^{1} / 2\right)$ than HDP-CDV, but the plasma AUC with oral HDP-CDV is substantially greater than ODBG-CDV. The relative oral bioavailability of HDP-CDV was estimated to be $88 \%$ versus $32 \%$ for ODBG-CDV (Table 1).

Tissue drug levels were assessed following oral administration of ODBG- $\left[2-{ }^{14} \mathrm{C}\right]-\mathrm{CDV}$ (Figure 2, panels B, C and D) and peak levels of radiolabeled CDV compared. Surprisingly, in the lung, oral ODBG-[2-- $\left.{ }^{14} \mathrm{C}\right]-\mathrm{CDV}$ gave peak levels of 111 nanomoles/g at 3 hours versus only 10 nanomoles/g in lung at the $1 \mathrm{hr}$ peak in the intraperitoneal group (Figure 2, panel B). Liver drug and metabolite levels, however, were higher with intraperitoneal administration than with oral. The peak level in liver was 72 nanomoles/g ( 1 hour) in the intraperitoneal group compared to peak levels of 9.1 nanomoles/g in the oral group (3 hrs) (Figure 2, panel C). Drug exposure to the liver was notably lower with oral ODBG-[2-14 C]-CDV than with intraperitoneal 
administration, suggesting that there is targeting of orally administered ODBG-[2-14 C]-CDV to lung. Drug levels in kidney peaked at $11 \mathrm{nmol} / \mathrm{g}$ ( $3 \mathrm{hrs}$ ) in the intraperitoneal group compared to 1.7 nanomoles/g (24 hrs) for the oral group (Figure 2, panel D).

\subsection{Comparison of ODBG-CDV and HDP-CDV pharmacokinetics}

The lung and liver levels of orally administered ODBG-[2- $\left.{ }^{14} \mathrm{C}\right]-\mathrm{CDV}$ and HDP-[2- $\left.{ }^{14} \mathrm{C}\right]-\mathrm{CDV}$ were compared (Figure 3). With oral administration of ODBG- $\left[2-{ }^{14} \mathrm{C}\right]-\mathrm{CDV}$, the lung $\mathrm{C}_{\max }$ was 100 -fold greater than oral HDP-[2- $\left.{ }^{14} \mathrm{C}\right]-\mathrm{CDV}$ in spite the fact that ODBG-CDV has a lower oral bioavailability. However, in liver, the $\mathrm{C}_{\max }$ of ODBG-CDV was only $21 \%$ of HDP$\mathrm{CDV}$ (Figure 3). We calculated the $\mathrm{AUC}_{0-72 \mathrm{hrs}}$ for the two compounds in liver, lung and kidney (Figure 4). HDP-CDV given orally provides large AUC values in liver (1360 nanomol/g/hrs) and small AUC values in lung ( 50 nanomol/g/hrs). Liver AUC values are 25 times greater than that of lung with HDP-CDV. However, when ODBG-CDV is given orally, the AUC in lung is larger than that of the liver (654 versus 319 nanomol $\mathrm{gm} \mathrm{hrs}$ ), representing a reversal of drug distribution from principally liver (HDP-CDV) to principally lung (ODBG-CDV). Kidney drug levels were low with both compounds.

To evaluate tissue levels of key drug metabolites, we prepared TCA extracts of liver and lung tissue from the single dose oral pharmacokinetic experiments and quantified liver and lung levels of CDV, CDVp and CDVpp at 3 hours by ion exchange HPLC as previously described (Aldern et al, 2003). With HDP-[2- $\left.{ }^{14} \mathrm{C}\right]-\mathrm{CDV}$, liver tissue contained readily detectable CDV and CDVp at 15.9 and 0.20 nanomoles/gm, respectively. In lung, these metabolites were below the level of detection (Table 2). However, with ODBG-[2-14C]-CDV, lung tissue contained CDV and CDVp, 1.10 and 0.26 nanomoles/gm, respectively, and liver tissue levels of CDV and CDVp were 1.10 and 0.11 nanomoles/gm (lower than noted with HDP-[2- $\left.{ }^{14} \mathrm{C}\right]-\mathrm{CDV}$ ) (Ciesla et al, 2003). Levels of the active antiviral, CDVpp, were below the level of detection with both analogs of CDV in lung and liver. However, these results clearly show that the lung is able to cleave ODBG-[2- $\left.{ }^{14} \mathrm{C}\right]-\mathrm{CDV}$ to $\mathrm{CDV}$ and carry out anabolic phosphorylation.

\subsection{In vivo antiviral activity of HDP-CDV and ODBG-CDV in ECTV infected mice}

We tested oral HDP-CDV and ODBG-CDV against high dose aerosol and intranasal lethal challenges of ECTV in A/NCR (A/JCr) mice as reported previously (Buller et al, 2004). Mice were challenged intranasally with $60,000 \mathrm{LD}_{50} \mathrm{~s}$ of ECTV and 4 hours after infection animals were treated orally with 2 or $8 \mathrm{mg} / \mathrm{kg}$ of HDP-CDV or ODGB-CDV (Table 3). Dosing was repeated daily for a total of 5 doses. Morbidity on day 7 was minimal or absent in treated animals, but was grade 2 or 3 in untreated, infected mice. At $2 \mathrm{mg} / \mathrm{kg}, 2$ of 10 animals died with HDP-CDV and ODBG-CDV at day 13-14, while all ten infected, untreated controls died at day 7.4. All animals treated with HDP-CDV or ODBG-CDV at $8 \mathrm{mg} / \mathrm{kg}$ survived. Animals were also challenged with 7,000 $\mathrm{LD}_{50} \mathrm{~s}$ of ECTV by the aerosol route and treated with 2 or 8 $\mathrm{mg} / \mathrm{kg}$ of HDP-CDV of ODBG-CDV as before and the results are shown in Table 4. No treated animals showed morbidity at day 7 . All untreated controls died with a mean day of death of $7.5 \pm 1.4$ days. With a dose of $8 \mathrm{mg} / \mathrm{kg}$ for 5 days, all animals treated with HDP-CDV and ODBG-CDV survived (8/8). At the lower dose of $2 \mathrm{mg} / \mathrm{kg}$ for 5 days, 8 of 8 mice survived with HDP-CDV and 7 of 8 with ODBG-CDV. From this data, we can conclude that ODBGCDV is equivalent to HDP-CDV is its ability to protect against lethal ECTV challenge in spite of its lower oral bioavailability.

\section{DISCUSSION}

CDV and other drugs can be directed to lung by making the alkoxyalkyl lipid ester more hydrophobic as we demonstrate here with ODBG-CDV. We hypothesize that this is because highly hydrophobic conjugates of CDV and other drugs are taken up by the enterocyte, exiting 
in the small intestinal lymphatics with the triglyceride-rich chylomicrons, instead of passing directly into the liver via the portal vein. Intestinal lymphatic lipids (chyle) drain via the thoracic duct successively into the left subclavian vein, innominate vein, superior vena cava, right side of the heart and hence, into the lung via the pulmonary artery (Gray, 1901). This may account for the very high levels of drug noted in the lung in the present studies. Levels of ODBG-CDV and its metabolites in the liver were reciprocally lower, consistent with this hypothesis.

Esterfication of CDV with 1-O-octadecyl-2-O-benzyl-sn-glycerol provides a compound which, when given orally, targets the lung and is orally bioavailable. Plasma levels show peak values at 6 hours for mice treated orally and 1 hour for mice treated by the intraperitoneal route. After 12 hours, drug levels decline at a similar rate with either route of administration. The lung AUC of the oral administration group was much greater than with intraperitoneal administration (Figure 2). Compared with HDP-CDV, the AUC of ODBG-CDV in lung is 13 fold greater (Figure 4) and levels of CDV and CDVp are detectable, showing that the lung can metabolize OBDG-CDV toward its active metabolite. Both HDP-CDV and ODBG-CDV given orally were equally active in providing protection from lethal challenges with ECTV administered by the intranasal route or in a small droplet aerosol. While lung levels of drug were greater with ODBG-CDV, mortality was similar to that observed with HDP-CDV. Although it has been suggested that death in lethal poxvirus infection is due to a pneumonitis, the precise cause of death in ectromelia virus infection is not known with certainty. In our earlier study with HDP-CDV, mortality in lethal ectromelia virus infection correlated with reduction of viral titer in liver and spleen, but did not correlate with reduction of lung viral titers (Buller et al, 2004). This is consistent with the possibility that death in lethal ectromelia infection is not due to the lung infectious process. Although the in vivo efficacy studies were done in A/NCR mice and the pharmacokinetics in Swiss Webster mice, both are albino mice strains and we have not noted any differences in pharmacokinetic behavior in NIH Swiss, Swiss Webster and CD-1 mice (unpublished observation).

First pass removal of oral drugs by the liver is a problem commonly encountered in drug development. Esterification of CDV to 1-O-octadecyl-2-O-benzyl-sn-glycerol increases lung exposure to drug while reducing liver area under curve. ODBG-CDV is essentially equivalent to HDP-CDV in reducing mortality in lethal aerosol ectromelia infections in mice. Other small molecules having suitable functional groups for linking may also be candidates for this approach. Disposition of other drugs esterified to 1-O-octadecyl-2-O-benzyl-sn-glycerol or 1O-octadecyl-2-O-benzyl-sn-glycerol-3-phosphate may provide targeting drugs to lung for microbial or neoplastic diseases while reducing drug taken up by the liver during oral absorption. A particularly good candidate for further study might be the ODBG-phosphate adduct of the non-orally active compound, zanamivir, for influenza.

\section{Acknowledgements}

The studies were supported by NIH grants AI-64615, AI-66499 and AI-29164 from NIAID (KYH) and NIAID contract NO1-AI-15436 (RMB). KYH has an equity interest and serves as a consultant to Chimerix Inc. The terms of the arrangements have been reviewed and approved by the University of California, San Diego in accordance with conflict of interest policies.

\section{References}

1. Aldern KA, Ciesla SL, Winegarden KL, Hostetler KY. The increased antiviral activity of 1-Ohexadecyloxypropyl-cidofovir in MRC-5 human lung fibroblasts is explained by unique cellular uptake and metabolism, Mol. Pharmacol 2003;63:678-681.

2. Beadle JR, Rodriquez N, Aldern KA, Hartline C, Harden E, Kern ER, Hostetler KY. Alkoxyalkyl esters of cidofovir and cyclic cidofovir exhibit multiple log enhancement of antiviral activity against cytomegalovirus and herpesvirus replication, in vitro, Antimicrob. Agents Chemother 2002;46:23812386. 
3. Buller RM, Owens G, Schriewer J, Melman L, Beadle JR, Hostetler KY. Efficacy of Oral Active Ether Lipid Analogs of Cidofovir in a Lethal Mousepox Model. Virology 2004;318:474-81. [PubMed: 14972516]

4. Ciesla SL, Trahan J, Wan WB, Beadle JR, Aldern KA, Painter GR, Hostelter KY. Esterfication of Cidofovir with Alkoxyalkanols Increases Oral Bioavailability and Diminishes Drug Accumulation in Kidney. Antiviral Res 2003;59:163-171. [PubMed: 12927306]

5. Gray, H. Gray's Anatomy. Bounty Books; New York, NY: 1901. p. 624

6. Guyton AC. Measurement of the respiratory volumes of laboratory animals. Am J Physiol 1947;150:70-77.

7. Kern ERC, Hartline C, Harden E, Keith K, Rodriguez N, Beadle JR, Hostetler KY. Enhanced inhibition of orthopoxvirus replication in vitro by alkoxyalkyl esters of cidofovir and cyclic cidofovir, Antimicrob. Agents Chemother 2002;46:991-995.

8. Lebeau I, Andrei G, Dal Pozzo F, Beadle JR, Hostetler KY, De Clercq E, van den Oord J, Snoeck R. Activity of alkoxyalkyl esters of CDV, cCDV and HPMPA against orthopox- and parapoxviruses in cell monolayers and in organotypic cultures. Antimicrob Agents Chemother 2006;50:2525-9. [PubMed: 16801436]

9. Quenelle DC, Collins DJ, Hostetler KY, Beadle JR, Wan WB, Kern ER. Oral Treatment of Cowpox and Vaccinia Infections in Mice with Ether Lipid Esters of Cidofovir, Antimicrob. Agents Chemother 2004;48:404-412.

10. Wan WB, Beadle JR, Hartline CB, Kern ER, Ciesla SL, Valiaeva N, Hostetler KY. Comparison of the Antiviral Activity of Alkoxyalkyl and Alkyl Esters of Cidofovir Against Human and Murine Cytomegalovirus Replication In Vitro, Antimicrob. Agents Chemother 2005;49:656-662.

11. Williams-Aziz SL, Hartline CB, Harden EA, Daily SM, Prichard MN, Kushner NL, Beadle JR, Wan WB, Hostetler KY, Kern ER. Comparative Activity Of Lipid Esters Of Cidofovir And Cyclic Cidofovir Against Replication Of Herpesviruses In Vitro, Antimicrob. Agents Chemother 2005;49:3724-3733. 
<smiles>CCCCOCC(COC)OCc1ccccc1</smiles>

ODBG-CDV<smiles>CCCCCCCOCCOP(=O)(O)CO[C@H](CO)Cn1ccc(N)nc1=O</smiles>

HDP-CDV

Figure 1.

Structures of 1-O-Octadecyl-2-O-benzyl-glycero-cidofovir and Hexadecyloxypropylcidofovir. 

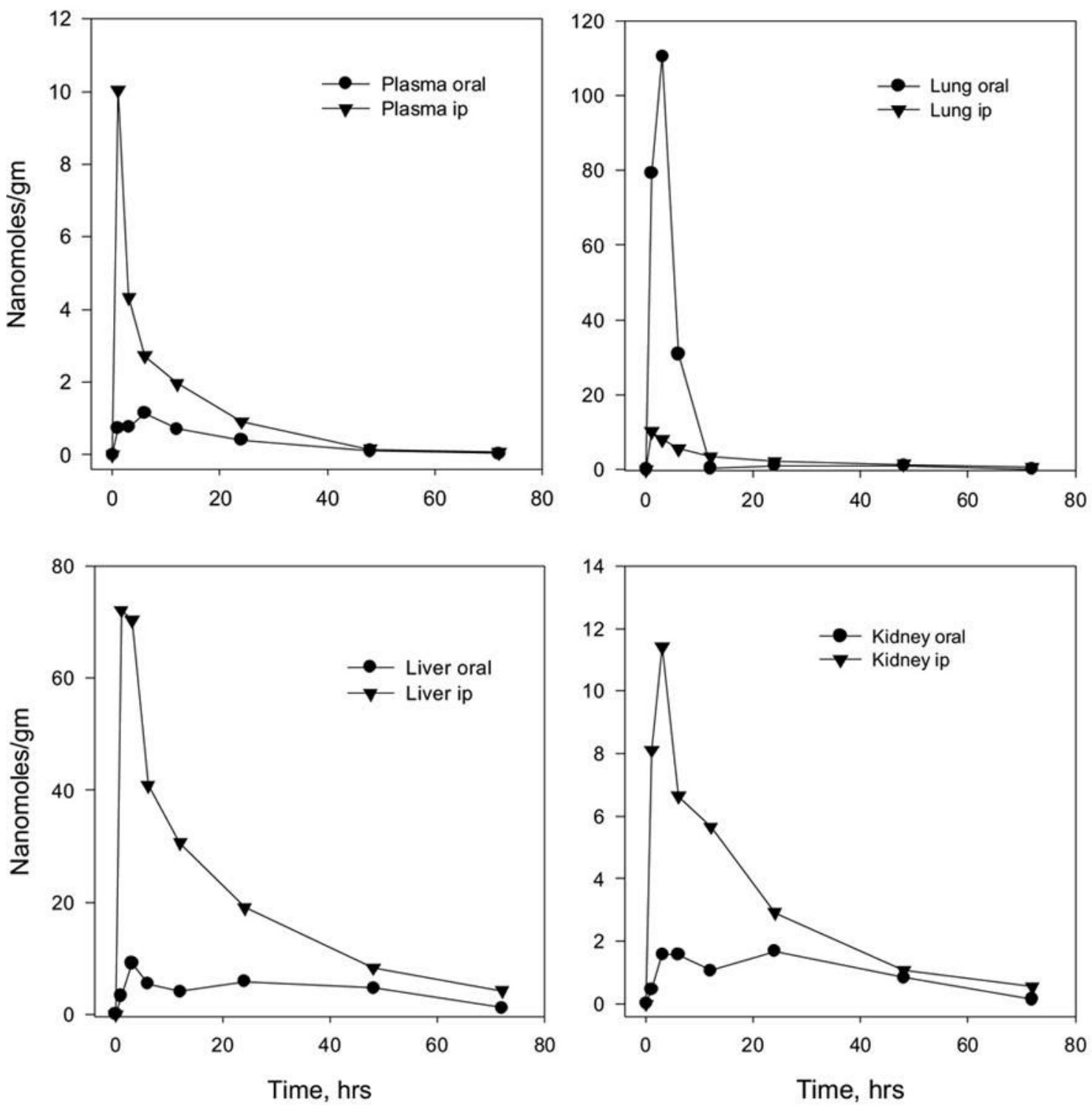

Figure 2.

Plasma and Tissue Distribution of Oral and Intraperitoneal Administration of $10 \mathrm{mg} / \mathrm{kg}$ of ODBG- $\left[2-{ }^{14} \mathrm{C}\right]-\mathrm{CDV}$ to Mice 

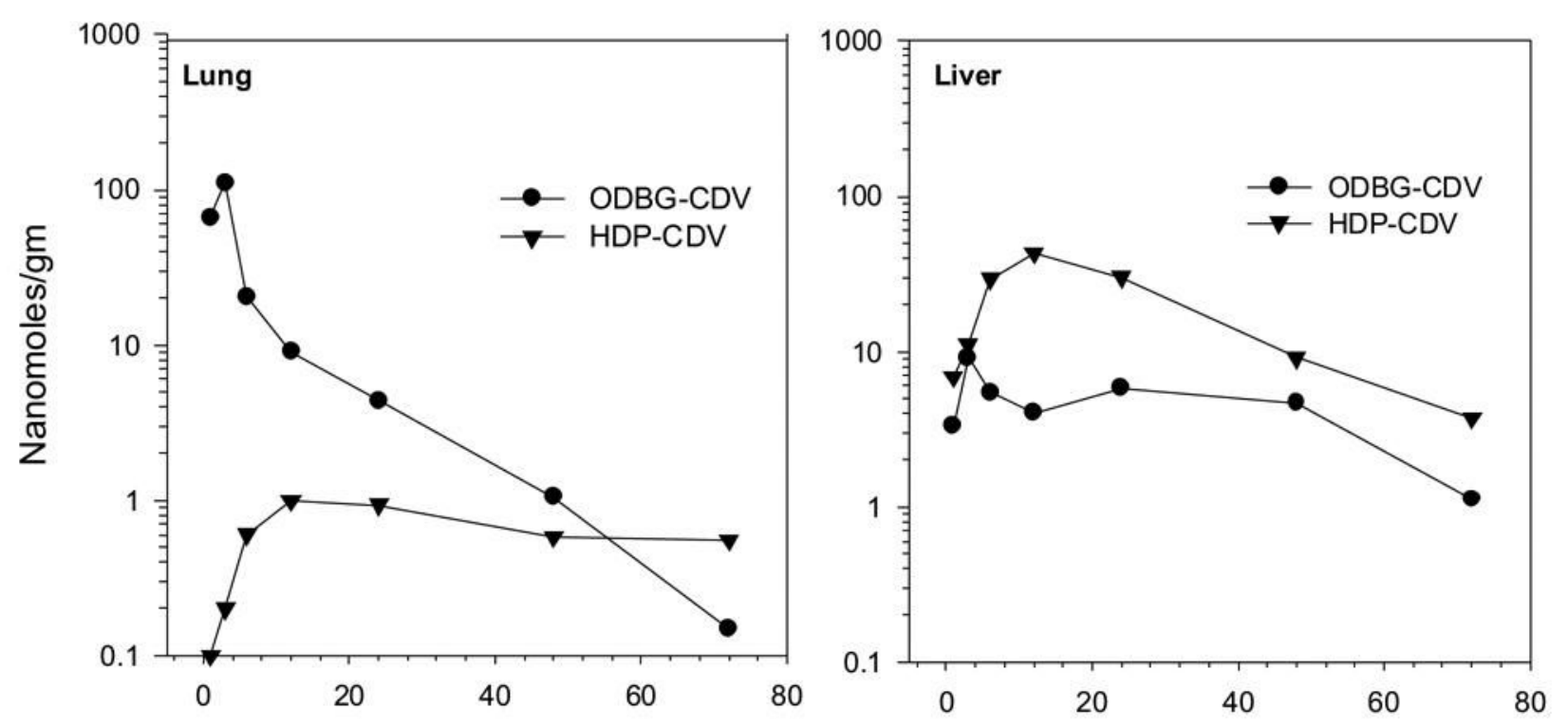

Time, hrs

Figure 3. Tissue Levels of ODBG-[2-14 C]-CDV and HDP-[2- $\left.{ }^{14} \mathrm{C}\right]-\mathrm{CDV}$ in Lung and Liver After Oral Administration of $10 \mathrm{mg} / \mathrm{kg}$ to Mice The HDP-CDV data was adapted from Ciesla et al, 2003. 


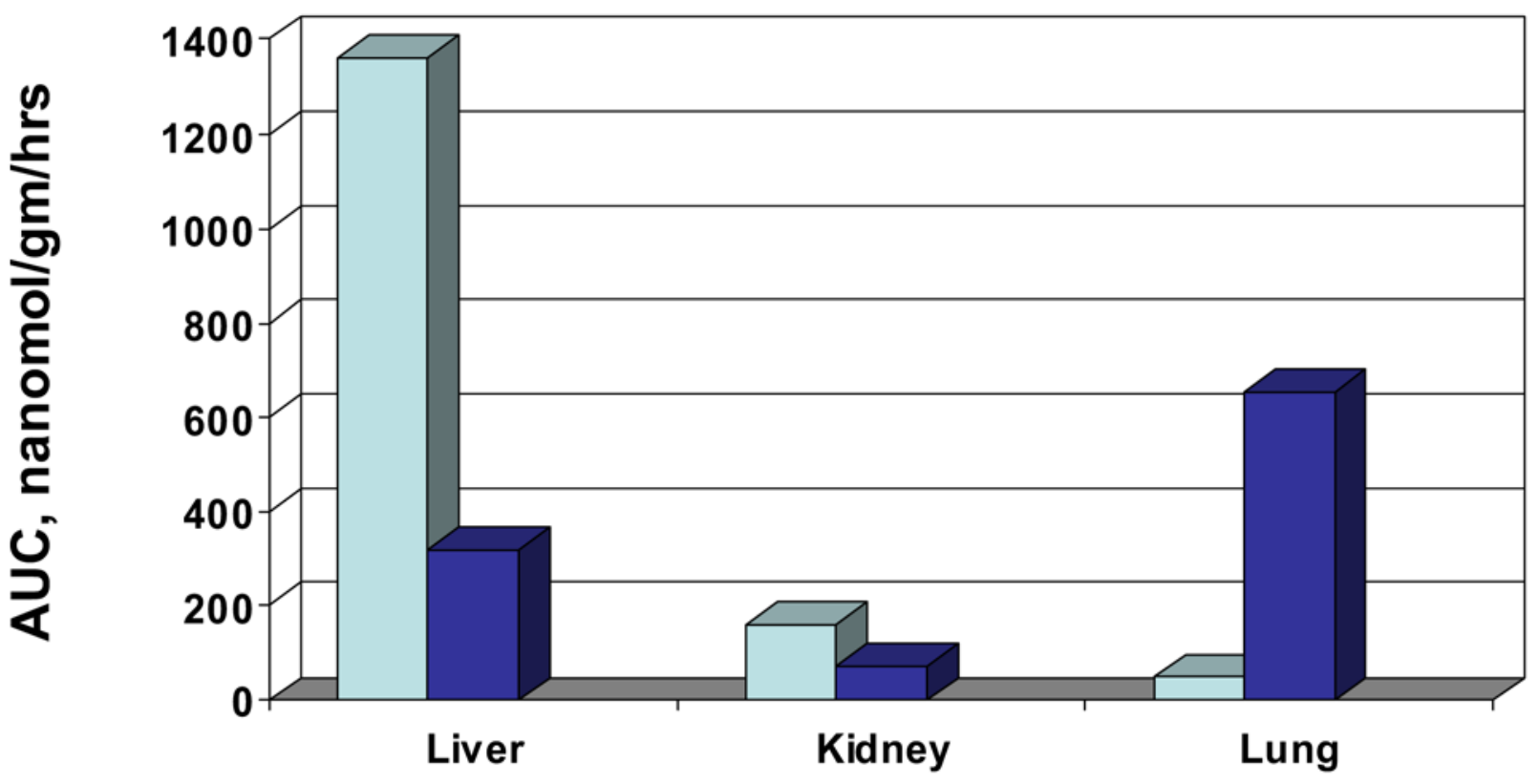

Figure 4. Area Under Curve Comparison: Oral HDP-[2- $\left.{ }^{14} \mathrm{C}\right]-\mathrm{CDV}$ Vs ODBG-[2- $\left.{ }^{14} \mathrm{C}\right]-\mathrm{CDV}$ in Liver, Kidney and Lung

A $10 \mathrm{mg} / \mathrm{kg}$ single oral dose of HDP-[2- $\left.{ }^{14} \mathrm{C}\right]-\mathrm{CDV}$ or ODBG-[2-14 $\left.\mathrm{C}\right]-\mathrm{CDV}$ was administered to mice and the area under curve (AUC) was determined from 0 to 72 hours in liver, kidney and lung. The HDP-CDV data was adapted from Ciesla et al, 2003. Light bars, HDP-CDV; dark bars, ODBG-CDV. 
Table 1

Plasma Pharmacokinetic Comparison of ODBG-CDV and HDP-CDV

\begin{tabular}{|c|c|c|c|c|} 
Compound & Plasma T1/2 & Plasma C $_{\text {max }}$ & Plasma T & Relative Oral Bioavailability \\
\hline ODBG-CDV & $16.9 \mathrm{hr}_{\text {max }}$ & $1.14 \mu \mathrm{M}$ & $6 \mathrm{hr}^{I}$ & $32 \%$ \\
\hline HDP-CDV $^{I}$ & $14.9 \mathrm{hr}^{I}$ & $2.37 \mathrm{uM}^{I}$ & $12 \mathrm{hr}^{I}$ & $88 \%{ }^{I}$ \\
\hline
\end{tabular}

Compounds were administered orally at a dose of $10 \mathrm{mg} / \mathrm{kg}$. Relative oral bioavailability was estimated by comparing the plasma area under curve obtained with oral versus subcutaneous ODBG-CDV.

${ }^{1}$ Data adapted from Ciesla et al, 2003. 
Table 2

CDV and Metabolite Levels in Liver and Lung After Oral Administration of $10 \mathrm{mg} / \mathrm{kg}$ ODBG-CDV or HDPCDV

\begin{tabular}{|c|c|c|c|c|}
\hline & \multicolumn{2}{|c|}{ 3 Hr Liver } & \multicolumn{2}{c|}{ 3 Hr Lung } \\
\hline Metabolite & HDP-CDV $^{2}$ & ODBG-CDV & HDP-CDV $^{2}$ & ODBG-CDV \\
\hline CDV & 15.9 & 1.10 & $<0.05$ & 1.10 \\
\hline CDVp & 0.20 & 0.11 & $<0.05$ & 0.26 \\
\hline CDVpp & $<0.05$ & $<0.05$ & $<0.05$ & $<0.05$ \\
\hline HPMPU & 0.90 & $<0.05$ & $<0.05$ & $<0.05$ \\
\hline
\end{tabular}

${ }^{l}$ For ODBG-CDV, extracts of liver and lung tissue were prepared and analyzed by HPLC as noted in Methods.

2 Frozen liver and lung tissues from HDP-CDV experiments reported by Ciesla et al., 2003, were stored at $-70^{\circ} \mathrm{C}$ and analyzed. Data are nanomoles/gm tissue. The limit of detection under these experimental conditions was 0.05 nanomoles/gm.

Abbreviations: CDV, cidofovir; CDVp, cidofovir monophosphate; CDVpp, cidofovir diphosphate; HPMPU, (S)-1-[3-hydroxy-2-(phosphonylmethoxy)propyl]uridine. 
Table 3

Efficacy of Oral HDP-CDV and ODBG-CDV in a High Dose Intranasal Challenge of A/NCR Female Mice with Ectromelia Virus

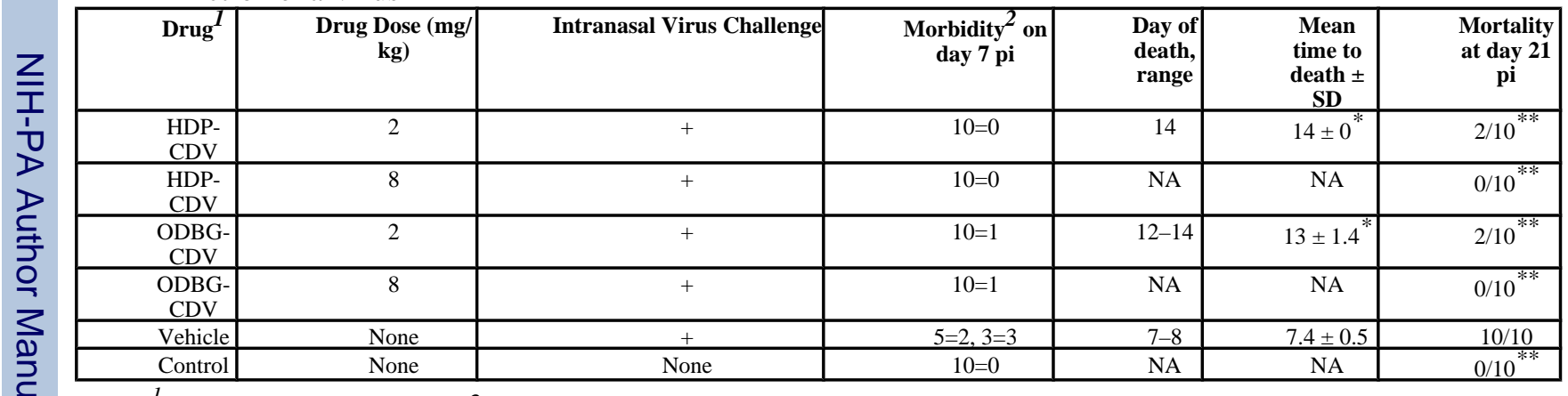

${ }^{1}$ Mice were infected with $3.0 \times 10^{3} \mathrm{PFU}(60,000 \times \mathrm{LD} 50)$ (5 $\mu$ l of virus suspension in 1 nare) of ECTV via intranasal route $\sim 4$ hrs prior to the first drug treatment. Treatment was repeated on days 1,2,3, and 4 with the indicated dose of drug in $100 \mu$ of vehicle. Mice treated with placebo received only 100 $\mu \mathrm{l}$ of sterile water on the same days.

orbidity $0=$ healthy, no signs of sickness; $1=$ face fur ruffled, no conjunctivitis; $2=$ face $\&$ body fur ruffled, hunched posture, eyes starting to swell; $3=2$ plus conjunctivitis; $4=3$ plus eyes swollen shut, near death, little or no movement, marked respiratory distress.

Abbreviations: pi, postinfection; NA, not applicable. P values versus vehicle treated animals:

$\mathrm{p}<0.05$;

* $\mathrm{p}<0.001$ 
Table 4

Efficacy of HDP-CDV and ODBG-CDV in a High Dose Aerosol Challenge of A/NCR Female Mice with Ectromelia Virus

\begin{tabular}{|c|c|c|c|c|c|c|}
\hline Drug $I$ & $\begin{array}{l}\text { Drug Dose (mg/ } \\
\text { kg) }\end{array}$ & Aerosol Virus Challenge & $\begin{array}{l}\text { Morbidity } \\
\quad \text { day } 7 \text { pi }\end{array}$ & $\begin{array}{l}\text { Day of } \\
\text { death, } \\
\text { range }\end{array}$ & $\begin{array}{c}\text { Mean } \\
\text { time to } \\
\text { death } \\
\pm \text { SD } \\
\end{array}$ & $\begin{array}{c}\text { Mortality } \\
\text { at day } 21 \mathrm{pi}\end{array}$ \\
\hline $\begin{array}{l}\text { HDP- } \\
\text { CDV }\end{array}$ & 2 & + & $8=0$ & $\mathrm{NA}$ & NA & $0 / 8^{* *}$ \\
\hline $\begin{array}{l}\text { HDP- } \\
\text { CDV }\end{array}$ & 8 & + & $8=0$ & NA & NA & $0 / 8^{* *}$ \\
\hline $\begin{array}{c}\text { ODBG- } \\
\text { CDV }\end{array}$ & 2 & + & $8=0$ & 13 & $13^{*}$ & $1 / 8^{* *}$ \\
\hline $\begin{array}{l}\text { ODBG- } \\
\text { CDV }\end{array}$ & 8 & + & $8=0$ & NA & NA & $0 / 8^{* *}$ \\
\hline Vehicle & None & + & $2=3$ & $7-11$ & $7.5 \pm 1.4$ & $8 / 8$ \\
\hline Control & None & None & $2=1$ & NA & NA & $0 / 8^{* *}$ \\
\hline
\end{tabular}

${ }^{1}$ Mice were exposed to a presented dose of $2.5 \times 10^{5} \mathrm{PFU}$ (7,000 x LD50) of ECTV via aerosol route $\sim 4$ hrs prior to the first drug treatment. Mice were treated on day $0,1,2,3$, and 4 with the indicated dose of drug in $100 \mu \mathrm{l}$ of vehicle. Mice treated with vehicle received only $100 \mu \mathrm{l}$ of sterile water on the same days.

Morbidity $0=$ healthy, no signs of sickness; 1 = face fur ruffled, no conjunctivitis; 2 = face $\&$ body fur ruffled, hunched posture, eyes starting to swell; $3=2$ plus conjunctivitis; $4=3$ plus eyes swollen shut, near death, little or no movement, marked respiratory distress. P values versus vehicle treated animals:

p $<0.05$

*** $<0.001$. Abbreviations as in Table 3 . 